\title{
Análise da precipitação pluvial de Pombal-PB relacionada com sistemas atmosféricos atuantes
}

\author{
An analysis of rainfall de Pombal PB related active weather systems \\ Maria de Fátima Araújo Alves ${ }^{1}$, Lígia Rejane Araújo Alves ${ }^{2}$,Erica Bento Sarmento ${ }^{3}$, Gêanny Alves de Lima ${ }^{4}$, Diêgo Lima
Crispim $^{5}$
}

Resumo: Uma das principais características do semiárido nordestino é a baixa disponibilidade pluvial. Diante do exposto, o objetivo do presente trabalho é analisar a variação da precipitação pluvial de Pombal/PB entre os anos de 1994 a 2010 verificando os sistemas atmosféricos que são responsáveis pelas as precipitações e depois comparar as chuvas desse período com as dos últimos quatros anos. Utilizou-se de dados de chuvas mensais de Pombal/PB, correspondente ao período de 1994 a 2010para uma análise das chuvas entre eles e após isso foi comparado às chuvas desse período com as de 2011 a 2014. Ambos os dados foram obtidos dos registros pluviométricos da Agência Executiva de Gestão das Águas do Estado da Paraíba (AESA). Nota-se que quanto mais distante do período chuvoso, mais seco ficam os meses. Isso ocorre devido a ZCIT se deslocar mais para o norte a partir de junho em virtude dos movimentos de rotação da terra provocando seca no semiárido. Constata-se que o regime pluviométrico de Pombal/PB é caracterizado por irregularidades, e os episódios de chuvas são associados a ZCIT.

Palavras-chaves: Sistemas meteorológicos, semiárido, chuvas.

\begin{abstract}
A main characteristic of the northeastern semi-arid region is the low availability rain. Given the above, the objective of this study is to analyze the variation of rainfall of Pombal / PB in the years from 1994 to 2010 checking weather systems that are responsible for the precipitation and then compare the rains of this period with the last four years. We used data monthly rainfall of Pombal / PB, corresponding to the period from 1994 to 2010 for an analysis of rainfall between them and after that were compared to the rains that period with 2011 to 2014. Both figures were obtained from the records precipitation of the Agência Executiva de Gestão das Águas do Estado da Paraíba (AESA). Note that the more distant the rainy season, are drier months. This is due to ZCIT move further north from June due to the earth's rotation movements causing drought in the semiarid region. It appears that the rainfall of Pombal / PB is characterized by irregularities and episodes of rains are associated with ZCIT.
\end{abstract}

Key words: Systems meteorological, semiarid, rains.

\footnotetext{
*Autor para correspondência

Recebido para publicação em 26/02/2015; aprovado em 03/06/2015

${ }^{1}$ Engenheira Ambiental, Universidade Federal de Campina Grande-UFCG, Pombal; Fone, E-mail: mariaufcg2013@gmail.com

${ }^{2}$ Graduanda em Engenharia Ambiental, Universidade Federal de Campina Grande-UFCG, E-mail:ligia.rejane@ yahoo.com.br

${ }^{3}$ Engenheira Ambiental, Universidade Federal de Campina Grande-UFCG; Mestranda em Ciência e Tecnologia Ambiental, Universidade Estadual da Paraíba.

E-mail: herycka2007@hotmail.com

${ }^{4}$ Graduanda em Engenharia Ambiental, Universidade Federal de Campina Grande-UFCG, E-mail: nanyt1@hotmail.com

${ }^{5}$ Engenheiro Ambiental, Universidade Federal de Campina Grande - UFCG; Especializando em Educação Ambiental e Geografia do Semiárido, Instituto

Federal do Rio Grande do Norte - IFRN; Mestrando em Sistemas Agroindustriais, Universidade Federal de Campina Grande - UFCG. Pombal-PB. E-mail:

diegolc_85@hotmail.com
} 


\section{INTRODUÇÃO}

A água é um elemento indispensável à vida e, por isso, constitui num dos maiores problemas sociais do mundo, ainda mais por que o crescimento populacional aumenta cada vez mais e utiliza esse recurso de forma irracional. A maior parte da região Nordeste do Brasil se situa dentro da zona semiárida, com grandes problemas para a sociedade e para os ecossistemas naturais, decorrentes das secas periódicas.

As regiões semiáridas têm, como característica principal, as chuvas irregulares, variando espacialmente e de um ano para outro, variando consideravelmente, até mesmo dentro de alguns quilômetros de distância e em escalas de tempo diferentes, tornando as colheitas das culturas imprevisíveis.

Não há duvida de que a precipitação pluvial é o elemento meteorológico que apresenta a maior variabilidade espacial e temporal, tanto em quantidade quanto em distribuição mensal e anual, e espacial, quando se compara o valor observado, ou mesmo esperado, de um local para outro dentro da própria região (ALMEIDA, 2001).

Uma das principais características do semiárido nordestino é a baixa disponibilidade pluvial com média entre 300 e $800 \mathrm{~mm}$. Isso intensifica a irregularidade na distribuição espacial e temporal (SILVA et al., 2005). Conforme Almeida et al (2010) no período chuvoso dessa região é comum acumular água em um certo local e em outro próximo não registrar nenhum milímetro, mostrando irregularidade na precipitação. Essa irregularidade das chuvas é devido a padrões de larga escala da atmosfera (SANTOS, 2012).

Diante do exposto, o presente trabalho objetivou-se analisar a variação da precipitação pluvial de Pombal/PB entre os anos de 1994 a 2010 verificando os sistemas atmosféricos que são responsáveis pelas as precipitações e depois comparar as chuvas desse período com as dos últimos quatros anos.

\section{MATERIAL E MÉTODOS}

\section{Localização da área de estudo}

O estudo foi desenvolvido no município de Pombal localizado no Estado da Paraíba. Esse município localiza-se na Mesorregião do Sertão Paraibano e Microrregião de Sousa, tem uma área de $889 \mathrm{~km}^{2}$, sendo uma das maiores cidade do Estado da Paraíba em dimensão territorial.

Figura 01. Localização do município de Pombal-PB.

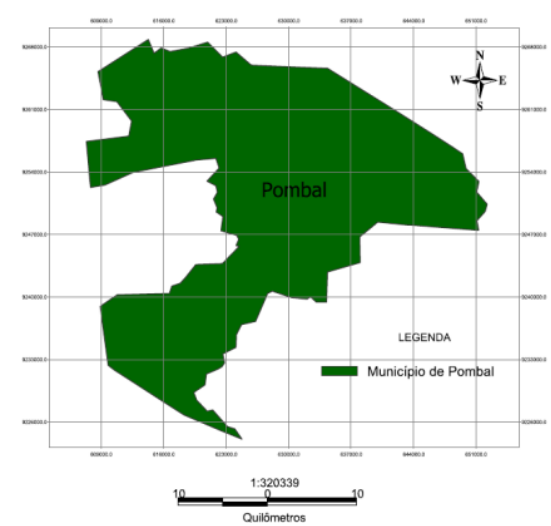

Fonte: CRISPIM (2015)
O município de Pombal-PB encontra-se inserido na bacia hidrográfica Rio Piranhas e da sub-bacia do Rio Piancó, situa-se a $184 \mathrm{~m}$ de altitude média do mar, com as coordenadas $06^{\circ} 46^{\prime} 12^{\prime}$ ' S e $37^{\circ} 48^{\prime} 07^{\prime}$ ' W e tem uma distância de $371 \mathrm{~km}$ da capital João Pessoa. Sua população é estimada para o ano de 2015 é 32.712 habitantes, segundo o censo do Instituto Brasileiro de Geografia e Estatística (IBGE, 2010).

De acordo com a classificação de Köppen o clima é Aw, do semiárido, com chuvas de verão e outono e a precipitação pluviométrica media anual de $800 \mathrm{~mm}$, sendo os meses de fevereiro, março e abril os que mais chovem, concentrando 60 a $80 \%$ do total da precipitação anual (MOURA et al., 2011).

A vegetação é basicamente composta por caatinga hiperxerófila com trechos de floresta caducifólia. O clima é do tipo tropical semiárido, com chuvas de verão (Beltrão et al., 2005).

\section{Dados utilizados}

Utilizou-se de dados de chuva mensal de Pombal/PB, correspondente ao período de 1994 a 2010 (16 anos) para uma análise das chuvas entre eles e após isso foi comparado às chuvas desse período com as de 2011 a 2014. Ambos os dados foram obtidos dos registros pluviométricos da Agência Executiva de Gestão das Águas do Estado da Paraíba (AESA).

Primeiramente, os dados foram consistidos e em seguida os mesmos foram tabulados em planilha eletrônica do programa Microsoft Excel, feito uma análise relacionada com os eventos atmosféricos responsáveis pelos os eventos de chuva e de seca nos valores de precipitação e em seguida foi calculada a média e mediana das precipitações. Após isso foi comparado as chuvas dos últimos 4 anos com todo o período analisado.

\section{RESULTADOS E DISCUSSÃO}

A figura 02 representa o mês de janeiro para os 16 anos analisados. Nota-se que a maior ocorrência de precipitação foi em 2004 com um total acumulado de 574,5 $\mathrm{mm}$. Essa precipitação foi devido à atuação dos ventos alísios do nordeste que se tornaram mais intensos que os de sudeste impulsionando a Zona de Convergência Intertropical (ZCIT) a atuar sobre a zona norte do NEB, além desse fator, outro que também contribuiu para isso foi à influência de um anômalo de umidade proveniente da Amazônia e do Oceano Atlântico fazendo com que as frentes frias do sudeste permanecessem mais tempo sobre essa região na baixa troposfera (ALVES et al., 2005). A ZCIT é o principal sistema atmosférico que interfere nas chuvas no semiárido paraibano (SANTOS, 2012).

Janeiro de 2004 foi caracterizado por intensas precipitações em todo o Nordeste do Brasil (NEB), e, sobretudo no sertão da Paraíba onde as chuvas foram distribuídas de forma crescente do litoral para o sertão (LIMEIRA et al., 2004).

Essas chuvas fortes e intensas segundo Alves et al. (2005) provocaram vários impactos tanto nas áreas urbanas quanto nas rurais como, por exemplo, inundações, enchentes, arrombamento de açudes e erosões nas estradas. Para Araújo et al. (2008) as chuvas intensas, apresenta distribuição irregular no tempo e no espaço e provoca muitos danos, entre 
eles: a erosão no solo, inundações, perdas aurículas, além de gerar problemas em reservatórios.

O mês de janeiro de 2004 não só para Pombal, mas para todo o estado foi marcado pela ocorrência de chuvas intensas em comparação aos demais meses desse ano. Os anos com o mês de janeiro mais seco foram 2001, 2006 e 2007 com 4,80; 2,30 e 2,10 mm.

Figura 02. Precipitação pluvial de janeiro no período de 1994 a 2010

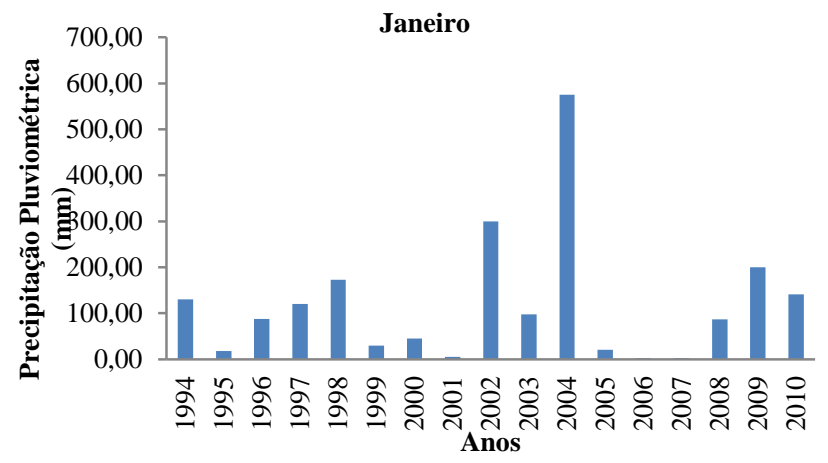

A Figura 03 mostra os dados de precipitação acumulada para os meses de fevereiro e março para o período de 1994 a 2010. Nota-se que fevereiro foi mais chuvoso para os anos de 2004, 2006 e 2007 com 437,90; 373,80; e 379,70 $\mathrm{mm}$. Observa-se que as chuvas extensas de janeiro (figura 2) ainda permaneceram atuando nos meses de fevereiro e março de 2004. Esses altos registros de chuva de acordo com a AESA foram provocados pelo o deslocamento das frentes frias para o norte, sob a atuação da Zona de Convergência Intertropical (ZCIT) e da banda de nuvens densas que se localiza ao longo do Equador e que se apresentou ao sul da sua posição normal, e à presença de Vórtices Ciclônicos em Altos Níveis (VCAN) sobre o Oceano Atlântico.

Conforme Araújo et al. (2005) as chuvas foram mais extremas para o mês de janeiro de 2004 (Figura 2), mas também se concentraram entre fevereiro e março, sendo março o mês mais chuvoso em 2008 e 2009. Esse período do ano é bastante chuvoso no semiárido paraibano (AESA, 2014).

Fonte: Autor (2015).

Figura 03. Precipitação pluvial do período de 1994 a 2010: (A) fevereiro e (B) março

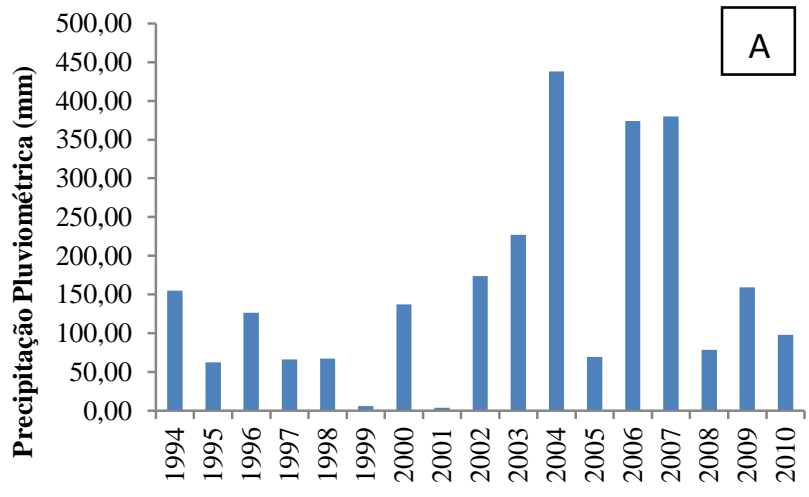

Anos

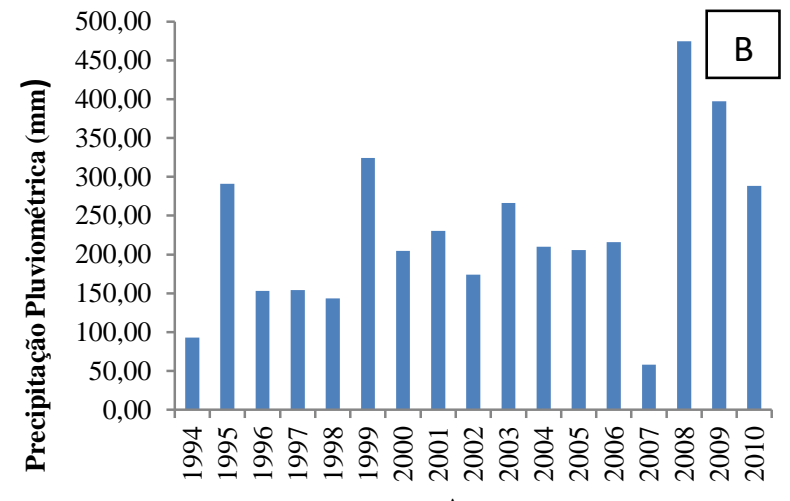

Anos

Fonte: Autor (2015).

Analisando a figura3 percebe-se que o ano em que mais choveu no mês de abril foi 1996 com 360, $80 \mathrm{~mm}$, seguido de 2008 com $333,70 \mathrm{~mm}$, já para o mês de maio foi o ano de 1995 com $257 \mathrm{~mm}$. Esses valores altos justificam o período chuvoso da região que segundo Júnior et al. (2008) se concentra entre fevereiro a maio.

Figura 04. Precipitação pluvial do período de 1994 a 2010: (A) abril e (B) maio.
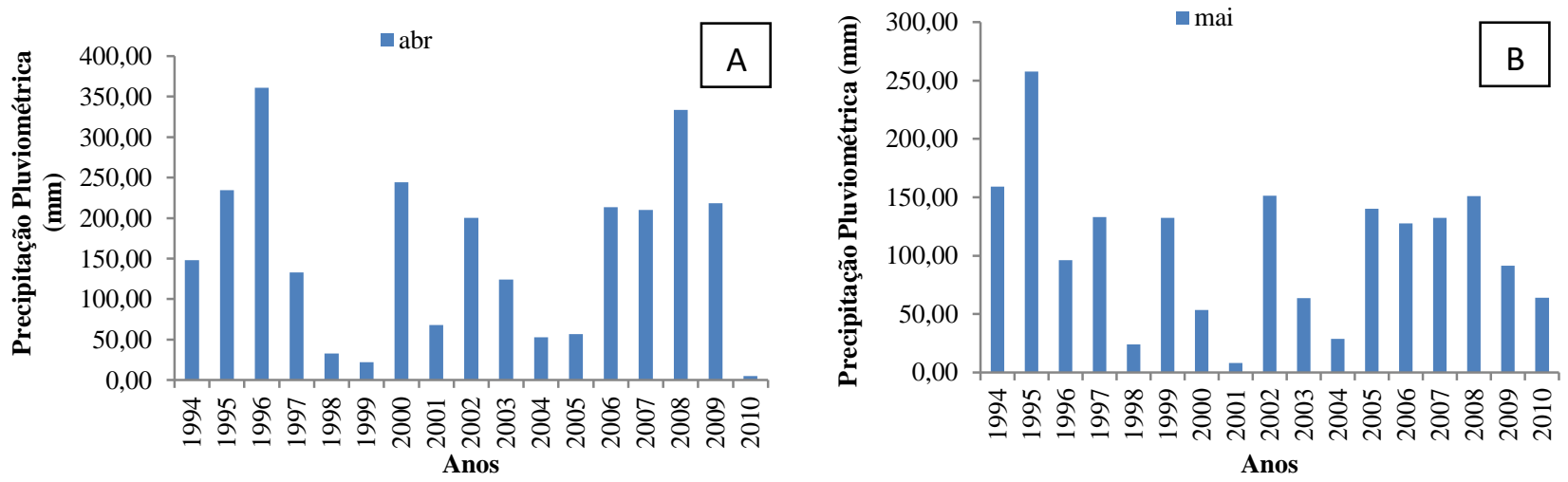

Fonte: Autor (2015)

Abril de 2010 foi o mês que menos choveu e quando isso ocorre faz com que Pombal confronte-se com períodos de escassez de chuvas, na época chuvosa, provocando as secas periódicas e, gerando perdas na produção agrícola e afetando a criação de animais (ARAÚJO et al., 2010). 
Na Figura 05 se encontram sintetizados os dados de precipitação do mês de junho e julho para o período estudado. Percebe-se que as chuvas de maiores volumes do mês de junho ocorreram no ano de 1994 com $183 \mathrm{~mm}$ e 2004 com 157,60 mm. Nos anos de 1997, 1998 e 2010 não ocorreram nenhuma precipitação e para os demais anos as chuvas já foram menores, e isso ocorrem em virtude de junho já ser o período seco da região em estudo (RODOLFO JÚNIOR et al., 2008). Já o mês de julho a altura máxima de água foi de 102 mm e em 2005 e 2010 não choveu nada.

Torres e Machado (2011) descreveram que episódios como esses são característicos do semiárido, uma vez que apresenta uma curta estação chuvosa com irregularidades das chuvas no tempo e no espaço, altas taxas de evapotranspiração e um longo período seco.

Figura 05. Precipitação pluvial do período de 1994 a 2010 : (A) junho e (B) julho.
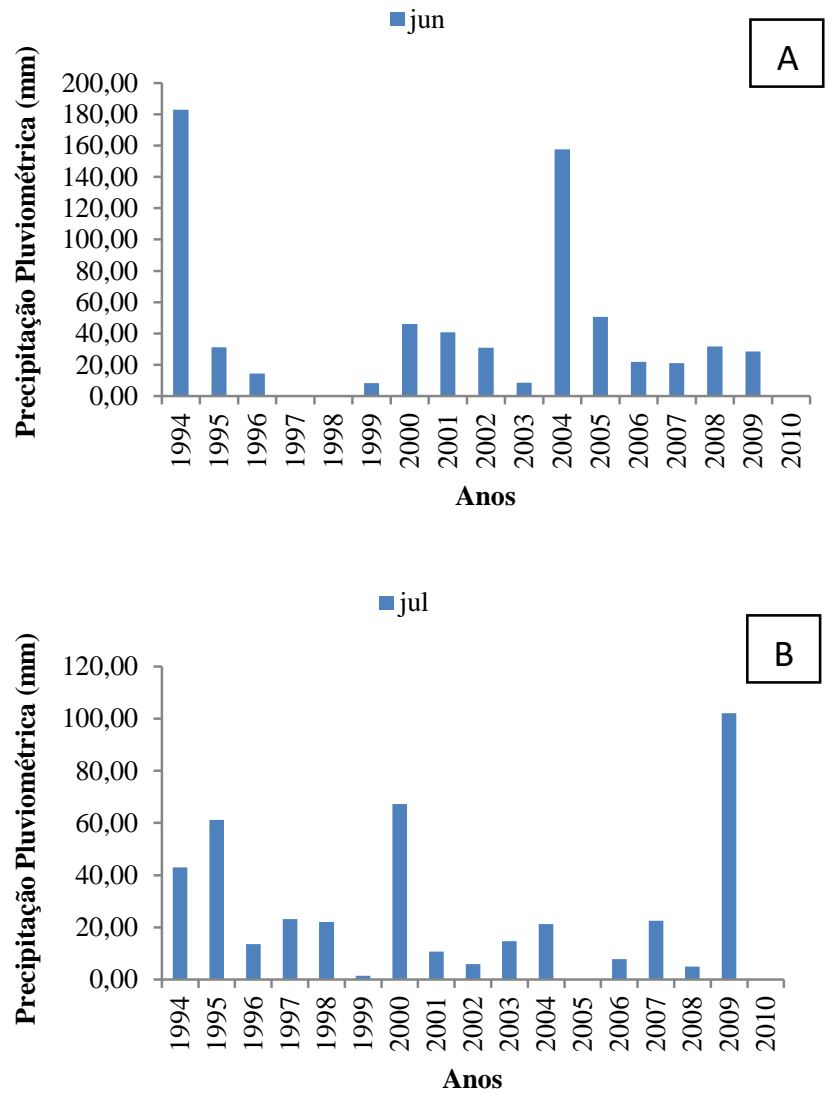

Fonte: Autor (2015).

A Figura 06 mostra os valores de precipitação de agosto e setembro desde 1994 a 2010. Observando a figura percebe-se a ausência de precipitação em quase todos os anos, exceto o agosto do ano de 2000 no qual foram registrados 47 e $40 \mathrm{~mm}$, mas ainda foram registradas chuvas em 1996, 1997, 1998, 2000, 2004, e 2006, porém os valores foram menores que os de junho e julho (figuras 6 e 7). Já setembro só houve chuva em 2000, 2002 e 2010 com o maior valor registrado 229,60 mm. Essa ausência de precipitação e suas irregularidades caracterizam a região como árida (SEIXAS 2004).
A ocorrência de precipitação para o ano de 2010 em setembro é justificado segundo o texto citado em Araújo et al. (2010) no qual relata que algumas chuvas de verão podem ocorrer entre os meses de setembro e outubro.

A redução nos valores de precipitação para os dois meses foi devido a Zona de Convergência Intertropical (ZCIT), o principal sistema atmosférico indutor de chuvas na Paraíba que a partir de junho se desloca mais ao norte devido os movimentos de rotação da terra provocando seca no semiárido (SANTOS, 2012).

Figura 06. Precipitação pluvial do período de 1994 a 2010: (A) agosto e (B) setembro.

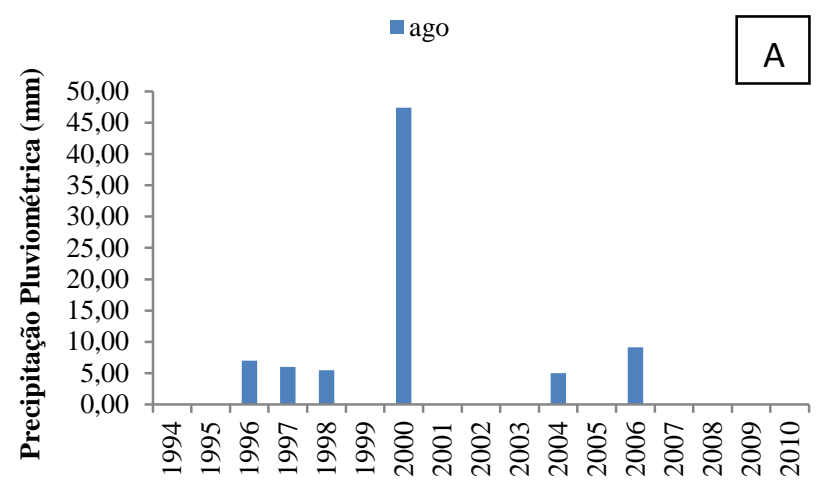

Anos

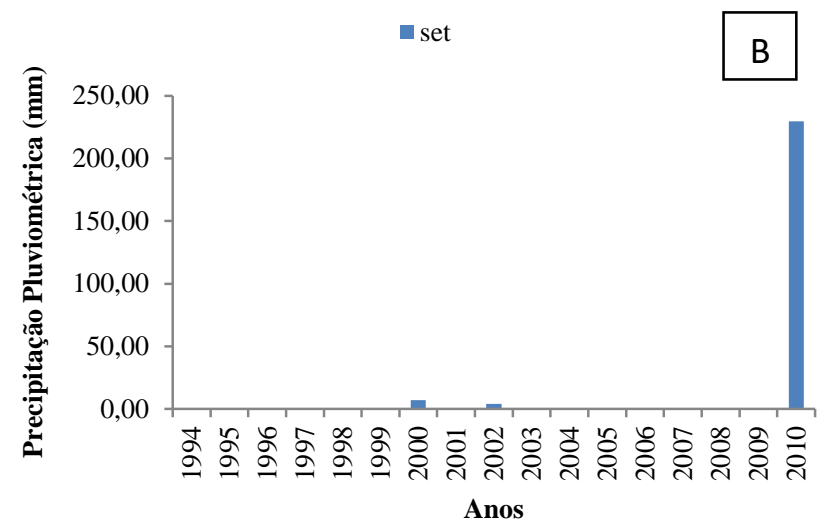

Fonte: Autor (2015).

A Figura 07 apresenta a precipitação para o período estudado para os meses de outubro e novembro. Nota-se que outubro choveu menos que novembro, o maior registro de chuva para esse mês foi de 18,2 em 2001. Em 1995, 1999 e 2006 também tiveram registros mínimos de precipitação. O mês de novembro já apresentou mais ocorrência de precipitação que nos anos de 1996, 1997, 1999, 2000, 2003, 2008, 2009 e 2010, sendo que o último ano apresentou o maior acúmulo de chuva com 172,2 mm.

Esses valores justificam a precipitação em épocas fora do período normal para as chuvas, e devem estar associados a eventos relacionados com a Temperatura da Superfície do Mar (TSM) (MOURA; VITORINO, 2012). 
Figura 07. Precipitação pluvial do período de 1994 a 2010: (A) outubro e (B) novembro.
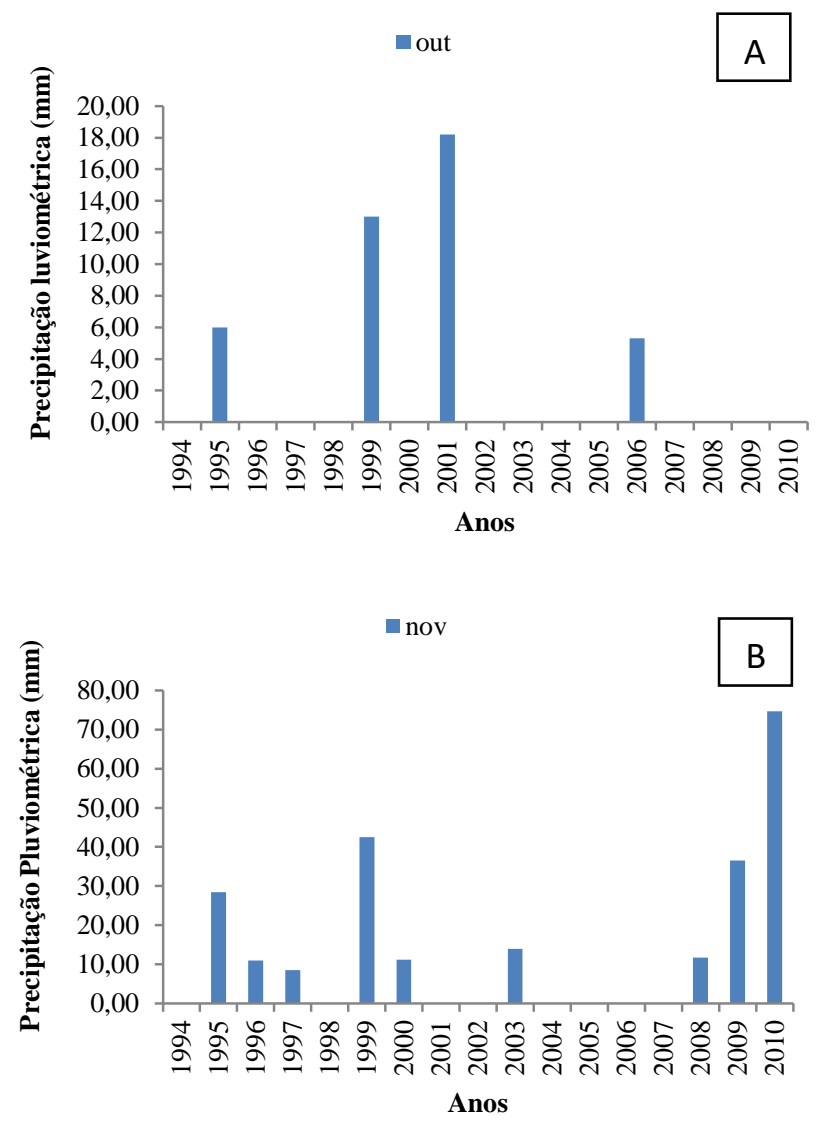

Fonte: Autor (2015).

A Figura 08 mostra a precipitação para dezembro do período estudado. Nota-se que choveu em alguns dos anos analisados. Os anos de 1995, 1998, 2002, 2006 e 2007 não tiveram acumulados de chuva. Os outros 10 anos apresentaram chuvas o que faz com que muitos dos autores citem que o período chuvoso de Pombal se inicia em dezembro a maio, como afirma Beltrão et al. (2005). Moura e Vitorino (2012) narram que essas chuvas ocorreram foram do período de atuação da ZCIT e devem estar associadas a variabilidade interanual.

Figura 08. Precipitação pluvial de dezembro no período de 1994 a 2010.

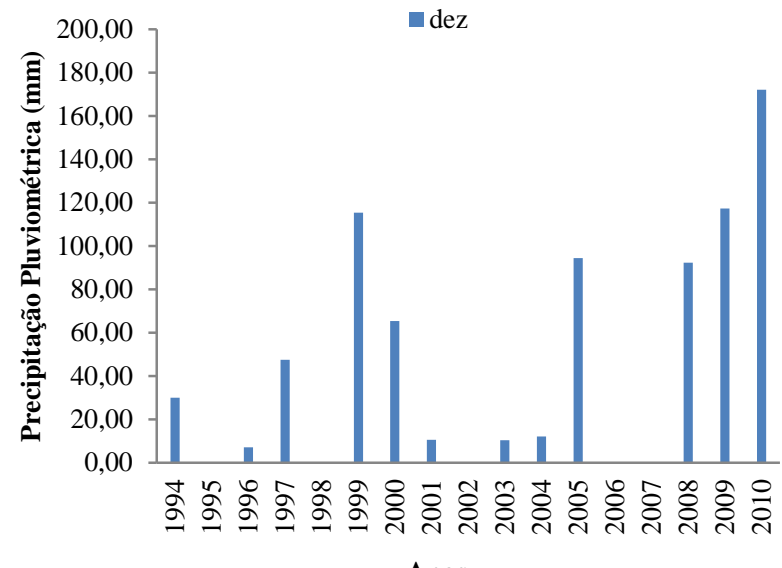

Anos
$\mathrm{Na}$ figura abaixo se encontram visualizadas as médias e medianas mensais da precipitação pluvial, de Pombal, PB. O mês mais chuvoso é março, enquanto o mês que menos choveu foi agosto. Nota-se uma variabilidade mensal, quando comparado um mês com o outro, esse fato está de acordo os resultados encontrados por Almeida e Silva (2004) que citam que a pluviosidade do semiárido paraibano apresenta esse comportamento.

Nota-se que o período chuvoso se concentrou entre os meses de janeiro a maio, sendo março o que mais chove, com média de $228,4 \mathrm{~mm}$. A partir de junho os valores de precipitação foram reduzindo, o que mostra que quanto mais distante do período chuvoso, mais seco ficam os meses. Isso ocorre devido a ZCIT se deslocar mais para o norte a partir de junho em virtude dos movimentos de rotação da terra provocando seca no semiárido (SANTOS, 2012).

As médias apresentam uma diferença entre os valores das medianas. Essa diferença conforme Almeida e Gomes (2011) indica que a distribuição é assimétrica.

Figura 09. Média e Mediana da Precipitação pluvial do período de 1994 a 2010.

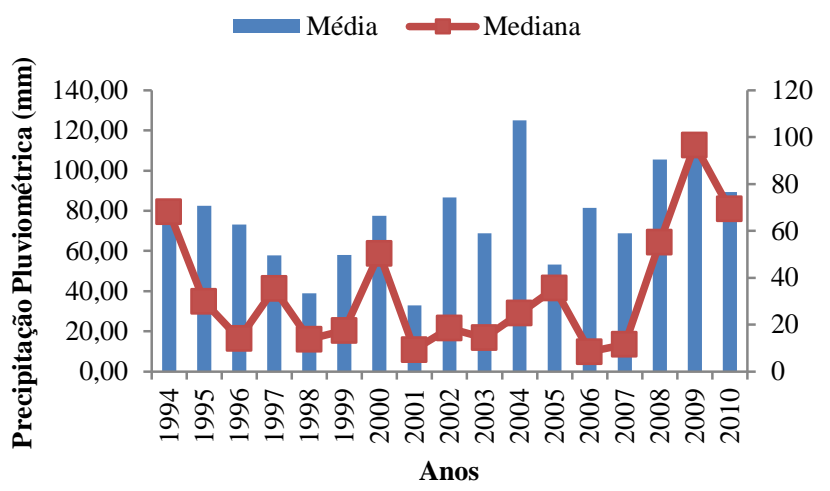

Fonte: Autor (2015).

Observando os valores de precipitação para cada ano analisado (Figura 9), nota-se que 2004 foi o ano em que houve o maior registro de acumulo de água e esse fato é explicado de acordo com Brito et al. (2004) que cita que a variação da precipitação pluvial na Paraíba é influenciada por diferentes sistemas meteorológicos que agem no Nordeste do Brasil e ainda conforme Nobree Molion (1988), essa variabilidade pluvial no nordeste brasileiro é o resultado do efeito combinado da atuação de múltiplos sistemas atmosféricos e das variações na intensidade e posição das circulações de Hadley e Walker, e ainda relacionada, com as mudanças nas configurações de circulação atmosférica de grande escala e com a interação oceano-atmosfera no Pacífico e no Atlântico. A atuação desses sistemas atmosféricos contribuiu para que 2004 tivessem os maiores valores de precipitação.

Fonte: Autor (2015). 
Figura 10. Precipitação pluvial do período de 1994 a 2010.

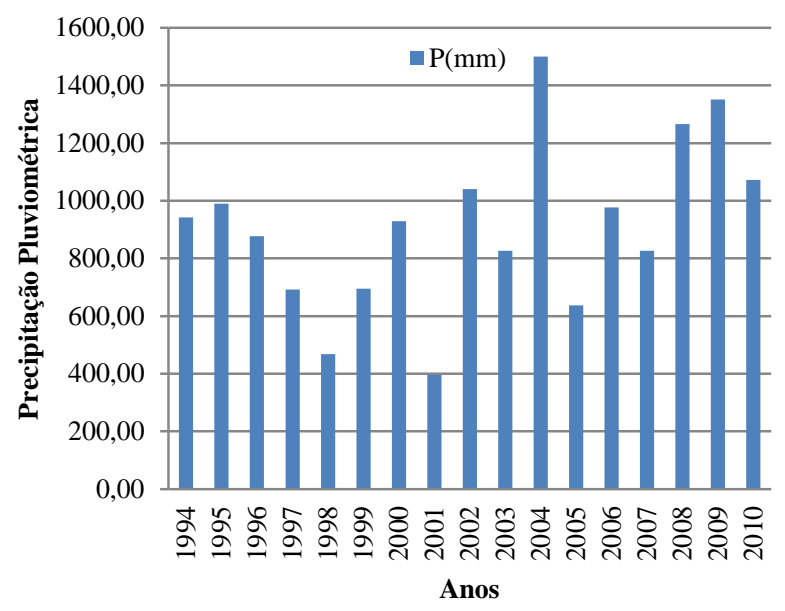

Fonte: Autor (2015).

Comparando o período de (1994 a 2010) com os últimos 4 anos (2011 a 2014) (Figura 11) nota-se que no segundo período analisado, houve redução dos valores acumulados de precipitação em anos seguidos, o que faz com que os reservatórios sequem e provoque transtornos a população sertaneja e isso é justificado de acordo com Cabral Júnior e Almeida (2012) que citam que ultimamente as chuvas vem se concentrando em apenas um a dois meses e em outros chovem torrencialmente, sendo caracterizadas pela elevada irregularidade espacial e temporal. Almeida e Sousa Neto (2005) descrevem que em regiões do semiárido paraibano já é normal constatar chuva em um local e muito próximo dele não chover nenhum milímetro, além disso, citam também que as chuvas ocorrem de forma diferenciada, em quantidade, distribuição e duração, sendo essas as características peculiares do regime pluvial nas diferentes microrregiões do Estado da Paraíba.

Figura 11. Precipitação pluvial do período de 1994 a 2014.

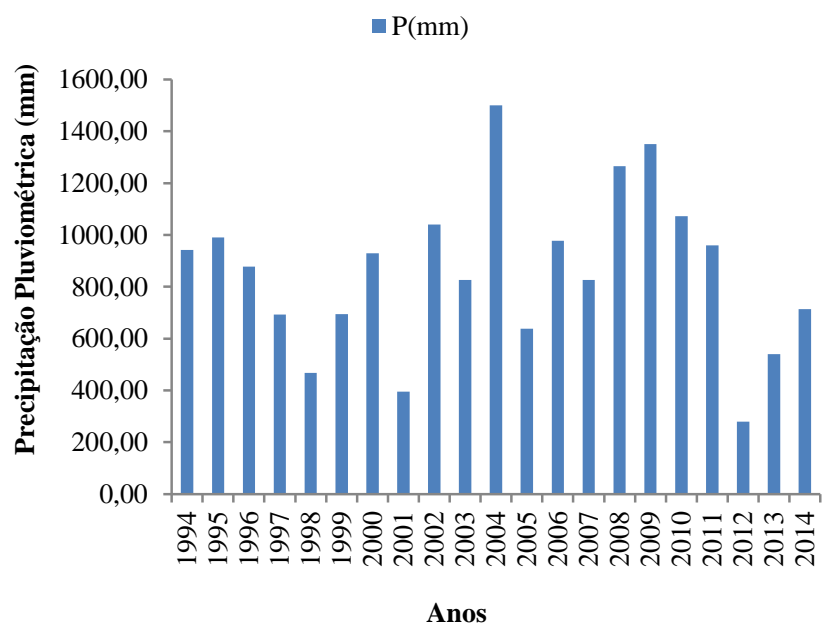

Fonte: Autor (2015)

\section{CONCLUSÕES}

Nota-se que o regime pluviométrico de Pombal/PB é caracterizado por irregularidades, e os episódios de chuvas são associados a ZCIT.

\section{REFERÊNCIAS BIBLIOGRÁFICAS}

AESA. Agência Executiva de Gestão das Águas do Estado da Paraíba. Disponível em: 〈http://www.aesa.pb.gov.br>. Acesso: 27 maio 2015.

ALMEIDA, H. A. ; FARIAS, M. P ; CABRAL JUNIOR, J. B. ; CABRAL, L. N . Variabilidade temporal e espacial da chuva nas localidades mais secas da Paraíba. In: Simpósio Brasileiro de Climatologia Geográfica, 9, 2010, Fortaleza, Anais... Fortaleza: SBCG, 2010.

ALMEIDA, H. A. de. Probabilidade de ocorrência de chuvas no Sudeste da Bahia. Ilhéus, CEPLAC/CEPEC. Boletim Técnico, n.182. 32p. 2001.

ALMEIDA, H. A. SOUSA NETO. G. M. de. Algumas características da precipitação na estação chuvosa do Sertão da Paraíba. In: 57 ${ }^{\mathbf{a}}$ REUNIÃO DA SBPC, Fortaleza, CE, 2005.

ALVES, J. M. B.; CAMPOS, J. N. B.; FERREIRA, F. F.; STUDART, T. M. C. As chuvas de janeiro/2004 no nordeste do brasil, suas características atmosféricas e seus impactos nos recursos hídricos da região. Departamento de Engenharia Hidráulica e Ambiental, 2005.

ARAÚJO, L. E. DE; SOUSA, F. DE A. S. DE; RIBEIRO, M. A. DE F. M.; SANTOS, A. S. dos; MEDEIROS, P. DA C. Análise estatística de chuvas intensas na bacia hidrográfica do Rio Paraíba. In: Revista Brasileira de Meteorologia, v.23, n.2, p.162-169, 2008.

ARAÚJO, L. E. et al. Variabilidade espaço-temporal das chuvas extremas na bacia do rio Paraíba no ano de 2004. In: Simpósio Internacional de Climatologia, 2005. Fortaleza: CE, 2005. 1 CD Rom.

ARAUJO, M. L. M. N. de; REINALDO, L. R. L. R.; SOUSA, J. da S.; ALMEIDA, P. G. de; ALVES, L. de S.; WANDERLEY, J. A. C. Impactos ambientais nas margens do rio Piancó causados pela agropecuária. Revista Brasileira de Gestão Ambiental, v.4, n.1, p. 13-33, jan./dez. 2010. Disponível em:< http://www.gvaa.com.br/revista/index.php/RBGA/article /view/461/1125>. Acesso em: 22 set. 2015.

BELTRÃO, B.A.; MORAIS, F.; MASCARENHAS, J. de C.; MIRANDA, J. L. F. de.; SOUSA JUNIOR, L. C. de.; MENDES, V. A. Diagnóstico do município de Pombal. Projeto cadastro de fontes de abastecimento por água subterrânea. Ministério de Minas e Energia/CPRM/PRODEM. Recife, 2005. 23p. Disponível 
em: <http://www.cprm.gov.br/rehi/atlas/paraiba/relatorio s/POMB147.pdf $>$. Acesso em: 20 set. 2015.

BRITO, J. I. B.; SILVA, M.C.L.; NÓBREGA, A. M.; BRAGA, C. C. Análise da precipitação do Estado da Paraíba no período de 1962-2001. In: XIII Congresso Brasileiro de Meteorologia, 2004, Fortaleza, SBMET, v. 1, Anais... 2004.

CABRAL JUNIOR, J. B.; ALMEIDA, H. A. de. Influência do fenômeno El-Niño sobre o regime pluvial na microrregião de Sousa, PB. REVISTA GEONORTE, Edição Especial, v.2, n.4, p. 904 - 915, 2012.

IBGE. Instituto Brasileiro de Geografia e Estatística. Censo Demográfico 2010. Rio de Janeiro: IBGE, 2010. Disponível em: 〈http://cod.ibge.gov.br/el8>. Acesso em: 22 jun. 2014.

LIMEIRA, R. C.; SOUSA, F. de A. S. de; SILVA, L. L. da. Desvios de precipitações no estado da Paraíba em janeiro de 2004. Disponível em: <www.cbmet.com/cbm.>. Acesso em: 14 ago. 2015.

MOURA, E. M. de.; RIGHETTO, A. M.; LIMA, R. R. M. de. Avaliação da Disponibilidade Hídrica e da Demanda Hídrica no Trecho do Rio Piranhas-Açu entre os Açudes Coremas-Mãe D’água e Armando Ribeiro Gonçalves. Revista Brasileira de Recursos Hídricos - RBRH, v. 16, n. 4, p. 07 - 19, 2011. Disponível em:< https://www.abrh.org.br/sgcv3/UserFiles/Sumarios/ceec e6ec0addde71990696726c2653c7_c03ea6f27190256a01 fbe6763e523f54.pdf>. Acesso em: 20 set. 2015.

MOURA, M. N.; VITORINO, M. I. Variabilidade da precipitação em tempo e espaço associada à Zona de Convergência Intertropical. Revista Brasileira de Meteorologia, v.27, n.4, p. 475 - 483, 2012.

NOBRE, C. A.; MOLION, L. C. B. The climatologic of drought prediction. Kluwer Academic Publishers. The impact of variation on agriculture, v. 2, 1988.

RODOLFO JUNIOR, F.; MELO, R. R. de; CUNHA, T. A. da; STANGERLIN, D. M. Análise da arborização urbana em bairros da cidade de Pombal no estado da Paraíba. Revista da Sociedade Brasileira de Arborização Urbana, v.3, n.4, p.3-19, 2008. Disponível em:< http://www.revsbau.esalq.usp.br/artigos_cientificos/artig o48.pdf>. Acesso em: 20 set. 2015.

SANTOS, E. A. Viabilidade no regime pluvial nas microrregiões do sertão da Paraíba nos anos de El Niño Oscilação Sul. Trabalho de Conclusão de Curso (Graduação em Geografia) da Universidade Federal da Paraíba, Centro de Educação, 2012.

SEIXAS, W. N. O Velho Arraial de Piranhas (Pombal) no Centenário de sua Evolução a Cidade, 1962. Edição ampliada e definitiva por Jerdivan Nóbrega e Verneck Abrantes. Editora Grafset, João Pessoa - PB, 2004.
SILVA, L., ALMEIDA, H. A., COSTA FILHO, J. F. Captação de água de chuvas na zona rural: uma alternativa para a convivência no semiárido nordestino. In: Simpósio de Captação de água de chuvas no semiárido, 5, Teresina, PI. CD-ROM, 2005.

TORRES, F. T. P.; MACHADO, P. J. de O. Introdução a Climatologia. São Paulo: Cengage Learning, 2011. 